\title{
Agmatine Ameliorates Nicotine Induced Lung Injury in Rats through Decrease TGF- $\beta 1$ and Bax Immunoexpression and by Anti-oxidative Sress Pathway: Histological, Immunohistochemical and Biochemical Study
}

\section{Ghalia M Attia ${ }^{1,2}$, Manar Ahmed Nader ${ }^{3,4}$, Rasha A Elmansy ${ }^{5,6}$ and Wael M Elsaed ${ }^{1,7 *}$}

${ }^{1}$ Department of Anatomy, Faculty of Medicine, Taibah University, Al Madina Al Monawarrah, Kingdom of Saudi Arabia

${ }^{2}$ Department of Histology and Cell Biology, Faculty of Medicine, Mansoura University, Al Mansoura, Egypt

${ }^{3}$ Department of Pharmacology and Toxicology, Colleague of Pharmacy, Taibah University, Al Madina Al Monawarrah, Kingdom of Saudi Arabia

${ }^{4}$ Faculty of Pharmacy, Mansoura University, Mansoura, Egypt

${ }^{5}$ Department of Anatomy and Embryology Faculty of Medicine, Ain Shams University, Cairo, Egypt

${ }^{6}$ Department of Anatomy, Unaizah Faculty of Medicine, AlQassim University, Al-Qassim, KSA

${ }^{7}$ Department of Anatomy, Faculty of Medicine, Mansoura University, Al Mansoura, Egypt

\begin{abstract}
Introduction: Nicotine (NIC), the chief alkaloid in tobacco, believed to be an active agent responsible for lungassociated diseases. This protocol targeted to analyze the ameliorating effect of agmatine (AG) on NIC induced lung damage.

Mateiral and methods: Forty-five adult male rats were divided into: Control group received intraperitoneal (IP) injection of distilled water, 2) NIC group recieved NIC (10 mg/kg/day) IP and 3) (NIC+AG) group treated by AG (10 $\mathrm{mg} / \mathrm{kg} /$ day) orally+NIC (10 mg/kg/day) by IP injection for 9 weeks. Total serum protein, triglycerides (TGs), total cholesterol (TC), high density lipoprotein (HDL), Low density lipoprotein cholesterol (LDL-C), malondialdehyde (MDA), superoxide dismutase (SOD), reduced glutathione (GSH) and vascular cell adhesion molecule 1 (VCAM1) were estimated. Lung specimens were prepared and stained with H\&E, Masson trichrome and immunehistochemical stains for assessment of transforming growth factor beta 1 (TGF- $\beta 1$ ) and Bax. Morphometric study followed by statistical analysis were done.

Results: NIC group showed elevation in serum levels of total protein, TC, LDL-C, TGs, MDA and VCAM-1 with evident diminishing in the serum levels of HDL-C, SOD, and GSH. Apoptosis and damage of alveolar epithelium and bronchiolar cells, marked fibrosis, inflammatory cell infiltrate and congestion of blood vessels were observed. Marked increase in the mean alveolar wall thickness, mean area\% of collagen fibers deposition, mean area\% of TGFB1 immuno-expression and mean number of Bax immune positive cells while a decrease in the mean linear intercept were detected. AG co-administered with nicotine ameliorated these biochemical, histopathological and morphometric changes.
\end{abstract}

Conclusion: AG ameliorates NIC induced lung damage in rats through improving the biochemical parameters and by decreasing TGF-ß1 and Bax immunoexpression.

Keywords: Agmatine; Lipid peroxidation; Lung toxicity; Nicotine; Rats; TGFB1 Bax

\section{Introduction}

Nicotine (NIC) is a chief toxic constituent of cigarette smoke. The detrimental effect of each cigarette attenuates life time by 11 min [1]. Earlier findings reported that NIC induced a large span of biological actions and is a primary risk factor in the enhancement of cardiovascular disorders, pulmonary disease and lung cancer [2]. Smoking induces an inflammatory response in the lung and shows a role in progression of obstructive pulmonary diseases (COPD) with a main influence on the health care sources, in the developed and developing countries [3,4]. NIC interrupts the mitochondrial respiratory chain causing an elevated liberation of hydrogen peroxide and superoxide anions [5]. NIC can enhance lipid peroxidation and cause depletion of antioxidants during induction of experimental vascular endothelial dysfunction [6].

Agmatine (AG), a biogenic amine formed by decarboxylation of L-arginine via the mitochondrial enzyme arginine decarboxylase, is broadly spread in mammalian tissues. AG has been reported to have various physiological and pharmacological actions displaying an enormous therapeutic prospective. It performs as a potential neurotransmitter in the brain $[7,8]$ and selectively inhibits iNOS, supplying evidence of the principal role in modulating NO generation
[9]. Earlier studies demonstrated numerous biological actions of AG including neuroprotective [10], cognitive, anxiolytic [11], anticonvulsant [12], antinociceptive [13] and antidepressant properties [14].

As a member of lung inflammation and fibrosis, TGF- $\beta$ is a member of a family of polypeptidic dimeric growth factors with three isoforms described in mammalians: TGF-beta 1, TGF-beta 2, and TGF beta 3 [15]. All human body cells produce and have receptors for this factor. This family has a vaster role in the regulation of cellular growth and

*Corresponding author: Elased MW, Department of Anatomy, Faculty of Medicine, Taibah University, Al Madina Al Monawarrah, Kingdom of Saudi Arabia, Tel: 00966595375920; E-mail: wzaarina@yahoo.com

Received May 18, 2017; Accepted June 20, 2017; Published June 29, 2017

Citation: Attia GM, Nader MA, Elmansy RA, Elsaed WM (2017) Agmatine Ameliorates Nicotine Induced Lung Injury in Rats through Decrease TGF- $ß 1$ and Bax Immunoexpression and by Anti-oxidative Sress Pathway: Histological Immunohistochemical and Biochemical Study. J Cytol Histol 8: 458. doi: 10.4172/2157-7099.1000458

Copyright: ( 2017 Attia GM, et al. This is an open-access article distributed under the terms of the Creative Commons Attribution License, which permits unrestricted use, distribution, and reproduction in any medium, provided the original author and source are credited. 
Citation: Attia GM, Nader MA, Elmansy RA, Elsaed WM (2017) Agmatine Ameliorates Nicotine Induced Lung Injury in Rats through Decrease TGF-ß1 and Bax Immunoexpression and by Anti-oxidative Sress Pathway: Histological, Immunohistochemical and Biochemical Study. J Cytol Histol 8: 458. doi: 10.4172/2157-7099.1000458

differentiation. TGF-beta is important mediator of lung inflammation and fibrosis process [15-17]

Apoptosis plays an essential part in the inflammatory processes [18]. One of the apoptotic activators is Bax, which is an integral membrane protein that bound to or associated with cytoplasmic organelles and can responds to various stimuli through migration to the mitochondria. This protein forms a heterodimer with Bcl-2, and acts as an apoptotic activator [19]

Lung is the principal objective for NIC induced oxidative injury and till now there is no prospective pharmacological therapy for such damaging effect. Although, previous studies reported protective effect of AG on lung tissues [20], yet reports concerning the protecting effects of AG against NIC-induced lung injury needs more investigation.

Therefore, the current study was designed to evaluate the influence of using AG on NIC-induced lung injury on the histological, immunohistochemical And Biochemical levels in rats aiming to explain its possible mechanisms.

\section{Materials and Methods}

\section{Drugs and chemicals}

Agmatine sulphate, nicotine and sodium thiopental were bought from Sigma Chemical Co. (Saint Louis, Mo, USA). All other chemicals used in this experiment were of acceptable analytical quality.

\section{Experimental animals}

Forty-five male albino rats of $180-220 \mathrm{~g}$ weight were used in this study. The rats were obtained from the Center of Nephrology and Urology, Mansoura University, Egypt and housed under traditional laboratory circumstances. The animals were delivered diet and water ad libitum. This research was conducted agreeing with the proper regulation for examinations in laboratory animals that were permitted by the Ethical Committee of Faculty of Pharmacy, Mansoura University, Egypt and in accordance with the National Institutes of Health guide for the care and use of Laboratory animals (NIH Publications No. 8023, revised 1978)

\section{Experimental design}

The rats were separated into three groups and each comprised of 15 rats.

1. Control group: rats received distilled water (NIC vehicle) by intraperitoneal (IP) injection for 9 weeks.

2. NIC group: rats were given NIC $(10 \mathrm{mg} / \mathrm{kg} /$ day $)$ by IP injection [21] for 9 weeks.

3. NIC+AG group: rats were treated by AG $(10 \mathrm{mg} / \mathrm{kg} / \mathrm{day})$ orally [22] and NIC10 mg/kg/day by IP injection for 9 weeks.

\section{Blood and tissue collection}

Latterly, rats were killed Animals killed by exsanguination under diethyl ether anesthesia $\left(1000 \mathrm{ml} / \mathrm{m}^{3}\right)$ [23]. The thoracic cavities were opened to expose the lung; the blood was taken via cardiac puncture and collected in non-heparinized tubes for biochemical analysis. Then the left lungs were detached and handled for microscopic study.

\section{Blood parameters measurement}

The serum Triglycerides (TG), total cholesterol (TC) and high density lipoprotein (HDL) cholesterol were estimated using Biomerieux kit (Marcyl, Etoile, France). Low density lipoprotein cholesterol (LDL-C) was estimated using the method of Friedewald and coworkers [24]. The protein level was assessed by Bradford's method [25]. Serum MDA, SOD and GSH levels were analyzed via Bio-diagnostic kits (Giza, Egypt). The level of VCAM-1 in serum was analyzed via Bender Med. Systems ELISA kit (Vienna, Austria).

\section{Light Microscopic Study}

Specimens from the left lung were taken and fixed in $10 \%$ neutral buffered formalin then washed with water, dehydrated in ascending grades of ethyl alcohol, cleared in xylene, and embedded in paraffin to obtain paraffin blocks. Serial lung sections were cut at 5 microns thickness and mounted on glass slides, de-paraffinized in xylene and stained by H\&E, Masson trichrome (MT) [26] and immunehistochemical stains for TGF $\beta$, and Bax in lung tissue using avidinbiotin-peroxidase complex techniques [27].

\section{Staining procedures for immunohistochemistry}

Using avidin-biotin-peroxidase complex procedure, paraffin lung sections were deparaffinized in xylene, rehydrated, rinsed in tap water, and embedded in $3 \% \mathrm{H}_{2} \mathrm{O}_{2}$ in phosphate buffer solution (PBS) for $10 \mathrm{~min}$ to block endogenous peroxidase. Sections were incubated overnight at $4^{\circ} \mathrm{C}$ with the respective primary antibodies; a monoclonal rabbit anti-TGF $\beta 1$ antibody (Clone TB21, MCA797, Serotec, Oxford, UK) at 1:200 dilution and monoclonal anti Bax antibody (Thermo Fisher Scientific $^{\text {tux }}$ Catalog no: MA5-14003, dilution 1:50). Following incubation with primary antibodies, the sections were incubated with the appropriate secondary antibody; a biotinylated anti-mouse IgG Incubation of sections in horseradish peroxidase-avidin biotin complex (Vectastain Elite, Vector, CA) for $30 \mathrm{~min}$ at room temperature were done then 3,3'-diaminobenzidine in $\mathrm{H}_{2} \mathrm{O}_{2}$ (DAB kit, Vector, $\mathrm{CA}$ ), was add to visualize the reaction as a brown colored product. Sections were then counterstained with hematoxylin and mounted. Negative control sections were obtained by the same steps of staining but without incubation with the primary antibodies.

\section{Morphometric Study \\ Mean linear intercept (MLI)}

Mean linear intercept is defined as the mean length of straightline segments on random test lines that cross the airspace between two sequential intersections of the alveolar surface with the test line. This means that the MLI includes the entire acinar airspace and not just alveoli [28].

Figure 1 shows the method of measurement of mean linear intercept (MLI) which based on intercept distribution. Linear intercepts were measured on microscopic images where test line segments are located at left, followed by a dashed line toward the right. The dashed line represents the guard line. In each time the test line intersects the alveolar wall, the distance to the next wall was measured. Borders of measurements of alveolar air spaces only are represented by letter (A) whereas alveolar and ductal air space together were represented by letter (D) and both measured distances were marked by arrows. (H\&E $\mathrm{x} 200$ ). This figure is modified from Knudsen et al. [28]

Mean linear intercept (MLI) and alveolar wall thickness were measured from H\&E stained section (x200 and x400 respectively). Area\% of collagen fibers deposition and TGF $\beta 1$ immuno-expression were measured from Masson trichrome stained sections $(\mathrm{x} 400)$ and anti TGF $\beta 1$ immuno-stained sections respectively. Number of Bax 


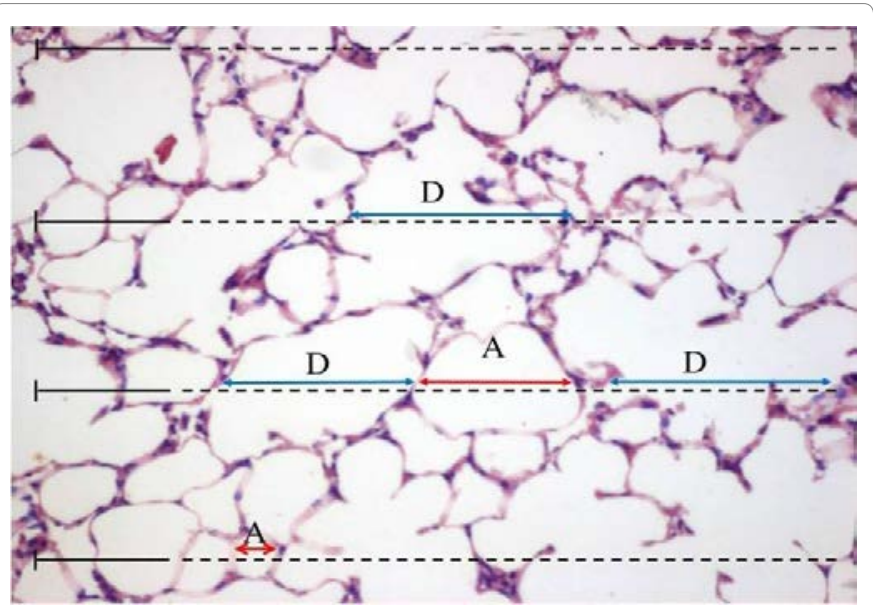

Figure 1: A photomicrograph of control rat lung shows the method of measurement of mean linear intercept (MLI). This figure is modified from Knudsen et al. [28]

immune-positive cells were measured from Anti-Bax immune-stained sections (x400). For all measures, three non-overlapping fields in each paraffin block for each rat were examined and photographed (i.e total measurements are 45 measurements /group). The photographs were analyzed using an Image Analyzer (Leica Q Win standard, digital camera CH-9435 DFC 290, Germany) with a measuring frame area $=786,432.0 \mu \mathrm{m}^{2}$. Morphometry was carried out at the Image Analysis Unit, Anatomy Department, Faculty of Medicine, Taibah University, Al Madinah Al Monawarrah, Saudi Arabia.

\section{Statistical analysis}

Statistical analysis was performed using IBM SPSS software version 21.00 (Chicago, Illinois, USA). Biochemical measures were statistically analyzed using one-way analysis of variance (ANOVA) followed by Tukey-Kramer multiple comparisons test. Statistical analysis for morphological lung measures were done using one-way analysis of variance (ANOVA), post-hoc and Fisher's least significant difference (LSD) were performed for inter-group comparison., All the results were presented as mean \pm standard error of mean (SEM). Statistical significance was considered when $P<0.05$.

\section{Results}

\section{Biochemical results}

Rats treated with NIC for 9 weeks demonstrated marked elevation in serum levels of total protein, TC, LDL-C, TGs, MDA and VCAM-1 with an evident reduction in the serum levels of HDL-C, SOD, GSH compared to their equivalent control rats. Rats treated with NIC coadministered with AG showed obvious amelioration in all the measured parameters as shown in Table 1. No gross malformations were detected in the lung tisssues.

\section{Histopathological and statistical Results}

$\mathrm{H} \& \mathrm{E}$ stained section of control group displayed typical lung construction with thin walled alveoli, alveolar sacs, terminal bronchioles and respiratory bronchioles. The alveolar septae were very thin, contained few cells and blood capillary. The lining cells of alveoli were formed of flat type I pneumocytes and cuboidal type II pneumocytes. Terminal bronchiole were lined with a single layer of cubical cells. (Figure 2A and 2B).

\begin{tabular}{|l|c|c|c|}
\hline & Control & NIC & NIC+AG \\
\hline Total protein $(\mathrm{mg} / \mathrm{ml})$ & $0.31 \pm 0.03$ & $2.57 \pm 0.27^{*}$ & $0.57 \pm 0.06^{\$}$ \\
\hline $\mathrm{TC}(\mathrm{mmol} / \mathrm{L})$ & $1.5 \pm 0.16$ & $4.62 \pm 0.47^{*}$ & $1.71 \pm 0.17^{\$}$ \\
\hline $\mathrm{LDL}-\mathrm{C}(\mathrm{mmol} / \mathrm{L})$ & $0.99 \pm 0.09$ & $3.23 \pm 0.34^{*}$ & $1.05 \pm 0.99^{\$}$ \\
\hline $\mathrm{HDL}-\mathrm{C}(\mathrm{mmol} / \mathrm{L})$ & $0.51 \pm 0.03$ & $0.09 \pm 0.01^{*}$ & $0.39 \pm 0.27^{\$}$ \\
\hline $\mathrm{TGS}(\mathrm{mmol} / \mathrm{L})$ & $0.35 \pm 0.01$ & $0.95 \pm 0.04^{*}$ & $0.45 \pm 0.05^{\$}$ \\
\hline $\mathrm{MDA}(\mathrm{nM} / \mathrm{L})$ & $12.79 \pm 1.19$ & $29.90 \pm 6.21^{*}$ & $15.97 \pm 1.37^{\$}$ \\
\hline $\mathrm{SOD}(\mathrm{U} / \mathrm{L})$ & $5.77 \pm 0.53$ & $1.35 \pm 0.13^{*}$ & $2.07 \pm 0.23^{\$}$ \\
\hline GSH $(\mu \mathrm{M} / \mathrm{L})$ & $1.99 \pm 0.13$ & $0.21 \pm 0.02^{*}$ & $1.45 \pm 0.13^{\$}$ \\
\hline $\operatorname{VCAM}-1(\mathrm{ng} / \mathrm{ml})$ & $9.98 \pm 0.94$ & $32.65 \pm 3.31^{*}$ & $12.09 \pm 1.14^{\$}$ \\
\hline
\end{tabular}

*Significantly different when compared to mean value of control and NIC groups, respectively using one-way ANOVA test followed by Tukey-Kramer multiple comparison tests.

NIC: Nicotine; AGM: Agmatine; TC: The Serum Total Cholesterol; TG: The Serum Triglycerides; LDL-C: Low Density Lipoprotein Cholesterol; HDL: High Density Lipoprotein Cholesterol; GSH: Glutathione; MDA: Malondialdehyde; SOD: Superoxide Dismutase VCAM-1: Vascular cell Adhesion Molecule-1.

Table 1: Effect of AG administration on different biological measures in NIC induced lung damage in rat.

NIC group showed marked disruption of lung architecture with abnormal shaped thick walled and collapsed alveoli, irregular shaped thick walled bronchioles and thick walled congested arterioles. Lining cells of bronchioles had small dark nuclei and some showed shredded dark cells and necrotic materials in their lumens. Respiratory bronchiole showed abnormal thick wall with two layers of cells; basal cubical and top flat layer in addition to a vacuolated substance most probably mucous was detected in their lumen. Some alveoli with destructed walls and very thick highly cellular inter alveolar septae which contained many macrophages, plasma cells and lymphocytes were observed. Moreover, in some alveoli, type I pneuomocytes became cubical instead of flat (Figure $2 \mathrm{C}-2 \mathrm{~F}$ ).

NIC+AG group showed nearly normal lung architecture with thin walled bronchus, bronchioles, arteriole, alveolar duct, alveolar sac and alveoli. Alveolar sac and alveoli appeared with minimally thickened septae which contained minimally congested capillaries. Alveolar walls were lined with nearly normal flat type I pneumocytes and large cuboidal type II pneumocytes (Figure $2 \mathrm{G}$ and $2 \mathrm{H}$ ).

A highly significant decrease in the MLI in NIC group (98.24 \pm 1.87) when compared to control group (213.33 \pm .63$)$ and a highly significant increase in NIC+AG group (194.36 \pm 4.15$)$ when compared to NIC group were observed. Also, the mean alveolar wall thickness showed a highly significant increase in NIC group $(91.60 \pm 2.48)$ when compared to control group $(32.62 \pm 1.00)$ and a highly significant decrease in NIC+AG group $(43.71 \pm 1.08)$ when compared to NIC group. $\mathrm{P} \leq 0.001$ among groups (Figure $2 \mathrm{I}$ ).

Masson trichrome stained sections of control group presented negligible amount of collagen fibers, concentrated mainly around basement membrane of the bronchus and blood vessels in addition to scares amount of collagen fibers in the alveolar septae (Figure 3A and 3B). In NIC group, an extensive amount of collagen fibers was detected in walls of terminal bronchioles, respiratory bronchioles, alveoli and blood vessels (Figure 3C and 3D).

NIC+AG group showed few amount of collagen fibers in bronchial and arteriolar, alveoli and alveolar sac walls (Figure 3E and 3F). A greatly marked elevation in the mean area\% of collagen fibers deposition in NIC group $(21.57 \pm 0.57)$ when compared to control group $(2.97 \pm$ $0.11)$ and a highly significant decrease in $\mathrm{NIC}+\mathrm{AG}$ group $(7.93 \pm 0.23)$ when compared to NIC group. $\mathrm{P} \leq 0.001$ among groups (Figure $3 \mathrm{G}$ ). 
Citation: Attia GM, Nader MA, Elmansy RA, Elsaed WM (2017) Agmatine Ameliorates Nicotine Induced Lung Injury in Rats through Decrease TGF-ß1 and Bax Immunoexpression and by Anti-oxidative Sress Pathway: Histological, Immunohistochemical and Biochemical Study. J Cytol Histol 8: 458. doi: 10.4172/2157-7099.1000458
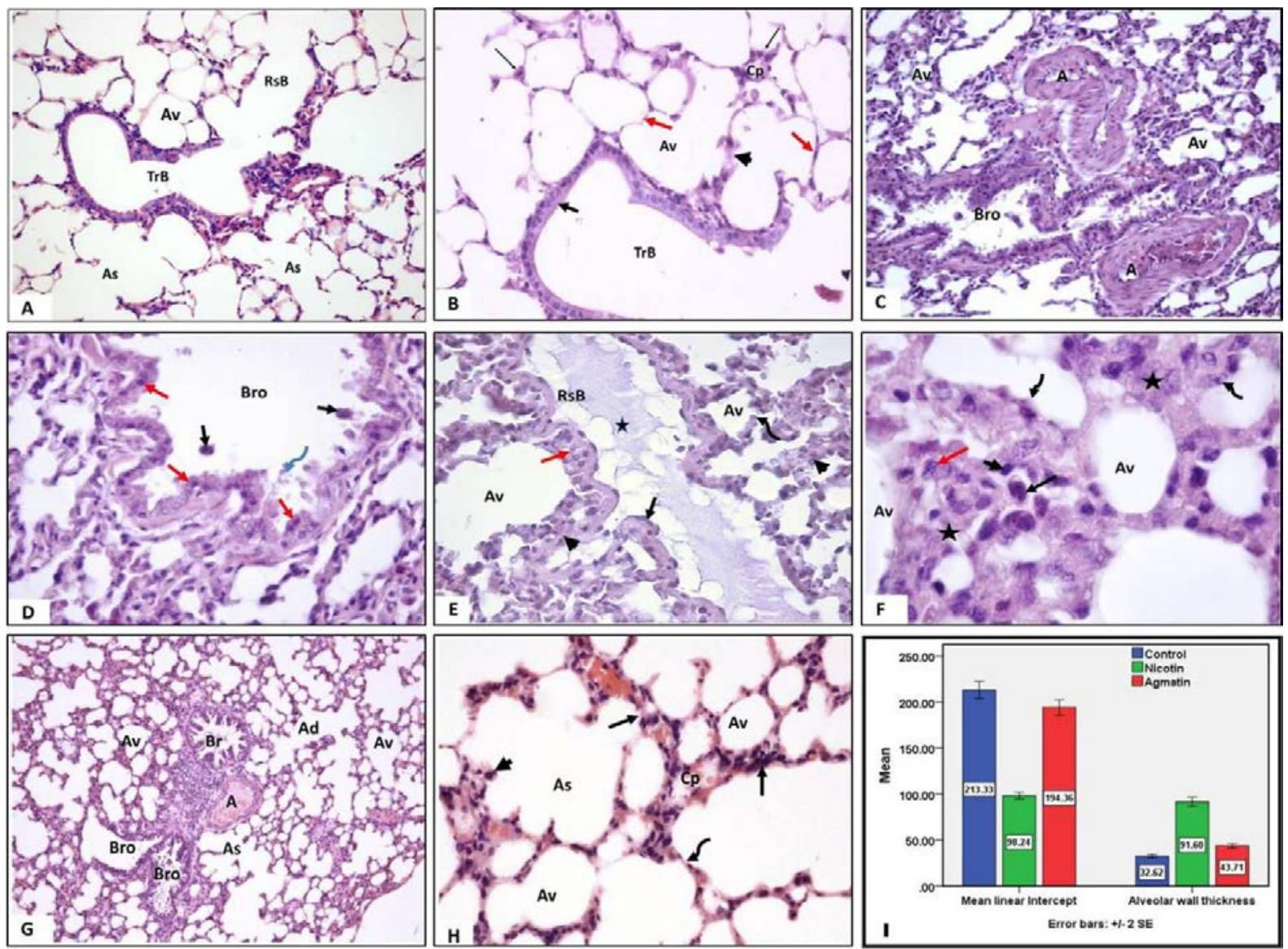

Figure 2: photomicrographs of lung sections from: (A and B); $A$ ): control lung showing normal architecture with thin walled alveoli (Av), alveolar sacs (As), terminal bronchioles (TrB) and respiratory bronchioles (RsB). B): High power magnification of previous figure showing that the alveolar septae (thin black arrow) are very thin which contain few cells and blood capillary $(\mathrm{Cp})$. The lining cells of alveoli are formed of flat type I pneumocytes (red arrow) and cuboidal type II pneumocytes (arrow head). Terminal bronchiole (TrB) are lined with single layer of cubical cells (thick black arrow). NIC group (C, D, E and F). C): Showing marked disturbance of lung architecture with abnormal shaped thick walled and collapsed alveoli (Av), irregular shaped thick walled bronchioles (Bro) and thick walled congested arterioles (A). D): Bronchiole (Bro) with many of its lining cells containing small dark nuclei (red arrows), shedding of some dark cells (black arrows) and necrotic materials (curved arrow) in its lumen. E): Respiratory bronchiole (RsB) has abnormal thick wall with two layers of cells; basal cubical (red arrows) and upper flat (black arrow). A vacuolated substance most probably mucous (star) is present in its lumen. Some alveoli (Av) showing destruction of their wall (curved arrow) and very thick highly cellular interalveolarseptae (arrow heads). F): Very thick highly cellular interalveolarseptae (stars) containing many macrophages (arrow), plasma cells (red arrow) and lymphocytes (arrow head). In some alveoli, type I pneuomocytes become cubical (curved arrows) instead of flat. NIC+AG group (G and $\mathrm{H}$ ); G): Showing nearly normal lung architecture with thin walled bronchus (Br), bronchioles (Bro), arteriole (A), alveolar duct (Ad) alveolar sac (As) and alveoli (Av). $\mathrm{H}$ ): Alveolar sac and alveoli with minimally thickened septae (arrows) which contain minimally congested capillaries (Cp) and alveolar walls which are lined with nearly normal flat type I pneumocytes (curved arrow) and large cuboidal type II pneumocytes (arrow heads). I): Clustered bars showing the MLI and mean alveolar wall thickness in Control, NIC and NIC+AG groups. P value is $\leq 0.001$ among groups. Values are represented as Mean \pm SEM $(H \& E$ stain; $(A$ and $C) \times 200 ;(B, D$, $\mathrm{E}$ and $\mathrm{H}) \times 400 ;(\mathrm{F}) \times 1000$ and $(\mathrm{G}) \times 100)$.

Anti-TGF $\beta 1$ immuno-stained sections of control group showed faint expression of TGF $\beta 1$ by some cells in the alveolar septae between alveoli and alveolar sacs (Figure 4A).

In NIC group, strong positive TGF $\beta 1$ immuno-expression was identified in cytoplasm of the epithelial cells lining the bronchioles, arterioles, alveolar wall and inter alveolar septae (Figure 4B and 4C). NIC+AG group exhibited mild expression of TGF $\beta 1$ in the epithelial cells lining of the bronchioles, alveoli, few cells in the wall of terminal bronchioles and alveolar sepata (Figure 4D and 4E). The mean area\% of TGF $\beta 1$ immuno-expression disclosed a vastly marked raise in NIC group $(17.67 \pm 0.36)$ when compared to control group $(0.98 \pm 0.03)$ and a highly significant decrease in NIC+AG group $(4.29 \pm 0.13)$ when compared to NIC group. $\mathrm{P} \leq 0.001$ among groups (Figure $4 \mathrm{~F}$ ).

Anti-Bax immune-stained section of control group showed negative Bax immunoreactions in the cells of the alveoli and alveolar sacs (Figure
5A). In NIC group, numerous Bax immune-positive cells within the epithelial lining of the bronchi and many cells in the lymphoid follicles were detected. The reaction was localized to the nuclei of positive cells. Moreover, Bax immune-positive nuclear reaction was exhibited by large number of type I and type II pneuomocytes (Figure 5B and 5C).

In NIC+AG group, few number of Bax immune-positive cells were seen in the epithelial lining of the bronchi and in the cells of alveoli group in addition to very few number of Bax immune-positive cells in the epithelial lining of terminal bronchioles and respiratory bronchioles(Figure 5D and 5E).

The mean number of Bax immune-positive cells presented a highly evident raise in NIC group $(64.47 \pm 1.85)$ when compared to control group $(2.11 \pm 0.16)$ and a highly significant decrease in NIC+AG group $(12.36 \pm 0.67)$ when compared to NIC group $(\mathrm{P} \leq 0.001$ among groups (Figure 5F). 
Citation: Attia GM, Nader MA, Elmansy RA, Elsaed WM (2017) Agmatine Ameliorates Nicotine Induced Lung Injury in Rats through Decrease TGF-ß1 and Bax Immunoexpression and by Anti-oxidative Sress Pathway: Histological, Immunohistochemical and Biochemical Study. J Cytol Histol 8: 458. doi: 10.4172/2157-7099.1000458
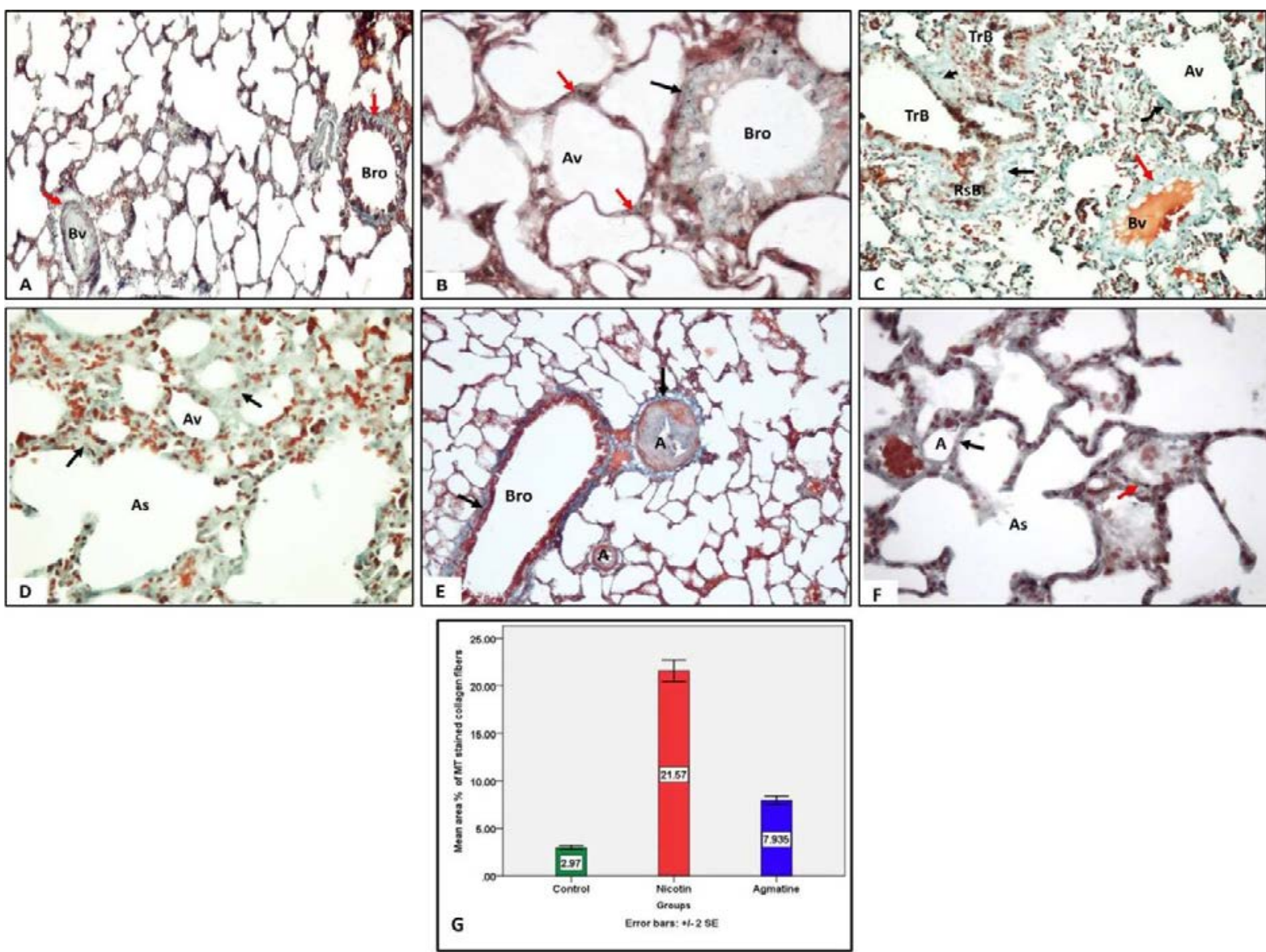

Figure 3: photomicrographs of Masson trichrome stained lung sections from: (A and B); A): Control lung with minimal amount of collagen fibers (red arrows) concentrated mainly around bronchus (Bro) and blood vessels (Bv). B): High power magnification of the previous figure showing scares amount of collagen fibers around basement membrane of the bronchus (Bro) and in the alveolar septae between the alveoli (Av). NIC group (C and D); C): Extensive amount of collagen fibers deposition (black arrows) in the walls of terminal bronchioles (Trb), respiratory bronchioles (RsB), the alveoli (Av) and the wall of blood vessels (Bv) (red arrows). D): Extensive thickening of the wall of the alveoli (Av) and alveolar sacs (As) (arrows). NIC+AG group (E and F); E): Few amount of collagen fibers (black arrows) are detected around bronchus (Bro) and around the wall (red arrows) of arterioles (A). F): Very mild thickening of the wall of the alveoli (Av) and alveolar sac (AS) by deposition of few amounts of collagen fibers (arrows). G): Clustered bars representing the mean area\% of collagen fibers deposition in Control, NIC and NIC+AG groups. $P \leq 0.001$ among groups; Values are expressed as Mean \pm SEM (MT stain; $A, C$ and $E \times 100 ; B, D$ and $F \times 400$ ).

\section{Discussion}

The current work investigated the possible protective function of AG on nicotine-induced lung injury. Several reports proved the key role of cholesterol and lipoproteins in pulmonary physiology. Circulating LDL and HDL are both taken up by the lung via particular receptors, and provide cholesterol to lung-resident cells, thus preventing local pulmonary cholesterol biosynthesis [29]. HDL act as the chief resource of the antioxidant vitamin E for alveolar epithelial type II cells [30], and supports surfactant generation by type II cells and growth of lung fibroblasts [31]. Though cholesterol is vital for type II cell function, extreme quantities of cholesterol worsen surfactant function, proposing the crucial importance of alveolar cholesterol homeostasis to normal lung physiology [32]. It has been shown that increased dietary cholesterol can alter surfactant synthesis, composition, and function [33] and reduction of serum cholesterol by several statins exhibited marked anti-inflammatory action in various lung disorders [34]. Diminution of cytokine and inflammatory cell production by simvastatin and pravastatin was observed in ovalbumin and house dust mite induced asthmatic mice [35].

The present work assessed the levels of serum lipid profile which are in accordance with previous research [35,36], all revealed marked elevation in serum TC, LDL-C, and reduction HDL-C upon treatment with nicotine, indicating marked lung injury. An effect that was reversed by the current treatment with $\mathrm{AG}$, was previously reported [37] .

To assess the probable mechanism for such beneficial effect of AG, oxidative burden was estimated and it was cleared that AG markedly ameliorated oxidative stress induced by 9 weeks nicotine injection in rat. This was reflected by a significant attenuation in serum MDA, SOD and GSH compared to nicotine group. AG treatment with nicotine in rat effectively normalized oxidant/antioxidant status. An in vivo study by Sudheer et al. [38] revealed that chronic NIC treatment in rat resulted in imbalance of prooxidant/antioxidant ratio. The mechanisms by which NIC enhanced oxidative pathway is partly due to its chemotactic action for polymorphonuclear leucocytes and aggravates the responsiveness of it to activate complement $\mathrm{C} 5 \mathrm{a}$, thus producing oxygen free radicals.

Another probable mechanism is the formation of cotinine and formaldehyde as metabolic products of nicotine by 5-hydroxylation. Such metabolites generated huge amounts of ROS [39]. Also NIC. interrupted the mitochondrial respiratory chain causing enhanced 
Citation: Attia GM, Nader MA, Elmansy RA, Elsaed WM (2017) Agmatine Ameliorates Nicotine Induced Lung Injury in Rats through Decrease TGF-ß1 and Bax Immunoexpression and by Anti-oxidative Sress Pathway: Histological, Immunohistochemical and Biochemical Study. J Cytol Histol 8: 458. doi: 10.4172/2157-7099.1000458
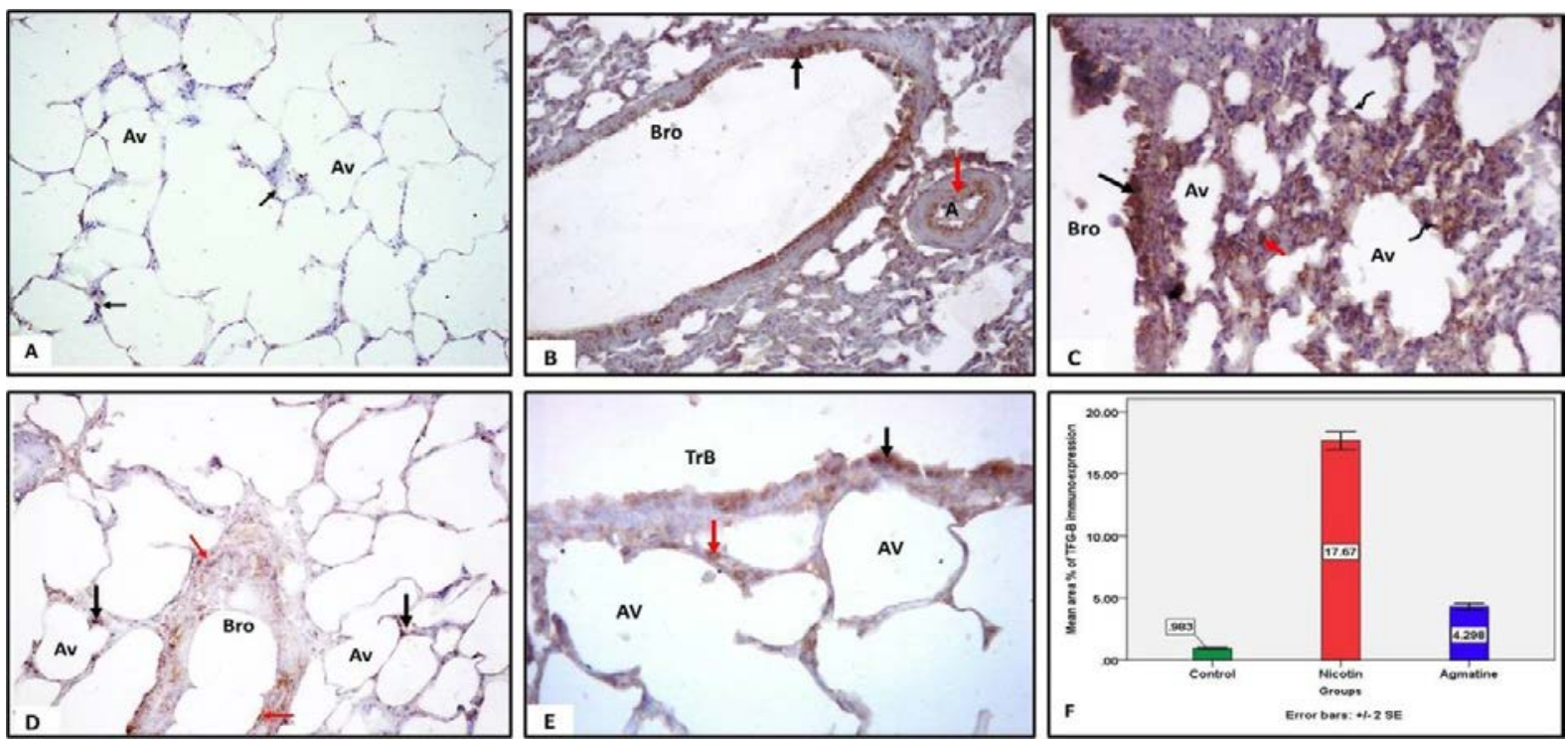

Figure 4: photomicrographs of Anti-TGF $\beta 1$ immuno-stained lung sections from A): Control group shows faint expression of TGF $\beta 1$ (arrows) by some cells in the alveolar septae between the alveoli (Av) and alveolar sacs (As). B): NIC group showing strong positive TGF $\beta 1$ immunoexpression in the epithelial cells lining (black arrows) of the bronchiole (Bro) and epithelial cells lining (red arrow) the arterioles (A). C) NIC group shows strong positive TGF $\beta 1$ immuno-expression in the epithelial cells lining (black arrows) of the bronchiole (Bro), cells (red arrow) which line the wall of the alveoli (Av) and the interalveolarseptae. D): NIC+AG group showing mild expression of TGF $\beta 1$ in the epithelial cells lining (red arrows) the bronchiole (Bro) and wall (black arrows) of the alveoli (Av). E): NIC+AG group with mild positive cytoplasmic TGF $\beta$ immune-expression by few cells in the wall (black arrow) of terminal bronchioles (TrB) and alveolar sepata (red arrow) between the alveoli (AV). F): Bars representing the mean area\% of TGF $\beta 1$ immuno-expression in Control, NIC and NIC+AG groups. P $\leq 0.001$ among groups; Values are expressed as Mean \pm SEM (Anti-TGF $\beta 1$ immunostain; A, B, C and D ×200, E ×400).
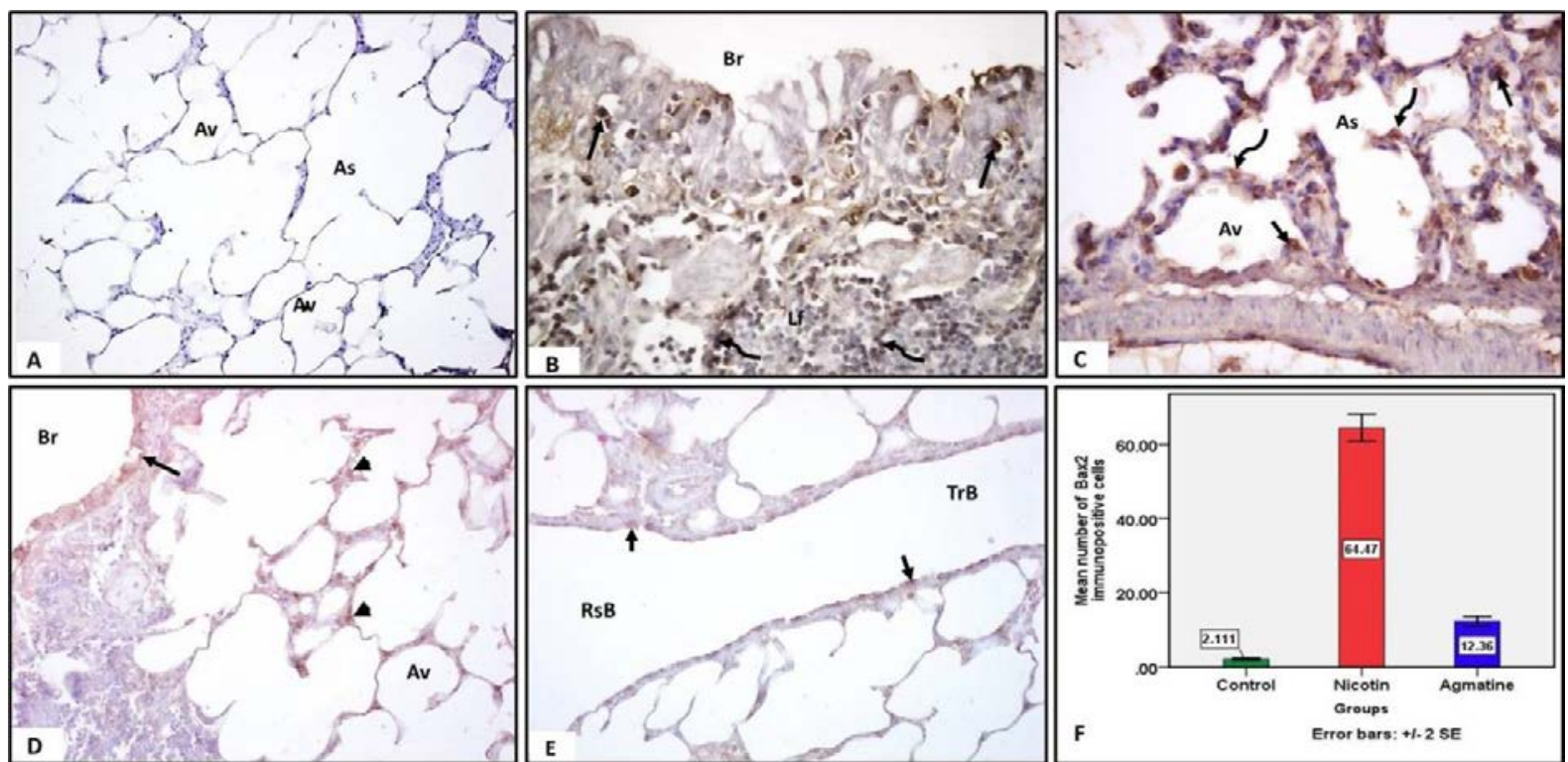

Figure 5: photomicrographs of Anti-Baximmune-stained lung sections from: A) Control group shows negative Baximmune-reaction (arrows) in cells of the alveol (Av) and alveolar sacs (AS). NIC group (B and C); B): Shows numerous Baximmune-positive cells (arrows) within the epithelial lining of the bronchus (Br) and many cells (curved arrows) in the lymphoid follicle (Lf). The reaction is localized to the nuclei of positive cells. C) Alveoli (Av) and alveolar sacs (As) with Baximmunepositive nuclear reaction which is exhibited by large number of type I (curved arrows) and type II pneuomocytes (arrows). NIC+AG group (D and E); D): Few number of Baximmune-positive cells which are detected in the epithelial lining (arrow) of bronchus (Br) and in the cells (arrow heads) of alveoli (Av). E): Show very few numbers of Baximmune-positive cells (arrows) in the epithelial lining of terminal bronchioles (TrB) and respiratory bronchioles (RsB). Bars represent the mean number of Baximmune-positive cells in the lung of Control, NICand NIC+AG groups. P $\leq 0.001$ among groups; Values are expressed as Mean \pm SEM (AntiBaximmune-stain; $A \times 100, B$ and $C \times 400$; $D$ and $F \times 200$ ).

production of superoxide anions and hydrogen peroxide [5]. All these factors play an important part in the progression of lipid peroxidation and elevated levels of MDA (lipid peroxidation end products). Endogenous antioxidant defense system including SOD, CAT, GPx, and GSH was declined in circulation, lung and liver of NIC administered rats [38]. The marked reduction in antioxidant status 
Citation: Attia GM, Nader MA, Elmansy RA, Elsaed WM (2017) Agmatine Ameliorates Nicotine Induced Lung Injury in Rats through Decrease TGF-ß1 and Bax Immunoexpression and by Anti-oxidative Sress Pathway: Histological, Immunohistochemical and Biochemical Study. J Cytol Histol 8: 458. doi: 10.4172/2157-7099.1000458

Page 7 of 9

in NIC group reflected that nicotine exhibited oxidative stress. The efficient amelioration of oxidant/antioxidant imbalance induced by AG was proved by Lee et al. [40] who postulated such ameliorating effect due to suppressing NF-кB activation in hyperglycemic rabbit mesengial cells and Iizuka et al. [41] proved such action via alpha-2 adrenergic signaling in retinal ganglion cells.

To further elucidate the effect of AG on NIC induced lung damage, VCAM-1 was also assessed. Increased airway inflammation was accompanied by enhanced oxidative stress and generation of pro-inflammatory molecules, including macrophage inflammatory protein-2 (MIP-2) and intercellular adhesion molecule-1(ICAM-1) and VCAM-1 [42,43]. ICAM-1/VCAM-1 are principle modulators for the stable adhesion of leukocytes, including neutrophils and lymphocytes in alveolar epithelial cells [43]. Rodella et al. [44] discovered marked elevation in VCAM-1 expression upon NIC treatment in vitro and in vivo respectively. Data of the existing study demonstrated that NIC treated animals had marked elevation in VCAM-1 activity. This elevation was evidently reduced upon treatment with AG. AG was hypothesized to act as an alternative substrate for endothelial nitric oxide synthase (eNOS) and hindering inducible nitric oxide synthase (iNOS) activity [45]. Consequently, AG may prevent the expression ofVCAM-1 via its antioxidant effect and enhancing eNOS activity.

The present work confirmed the relation between such biochemical changes and the resultant histological alterations of lung tissue. NIC treated lung group showed marked disturbance of lung architecture in the form of thick walled collapsed alveoli, irregular thick walled bronchioles, thick walled congested arterioles, extensive deposition of collagen fibers and inflammatory cells infiltration. Statistically, there was a highly marked decrease in MLI and a greatly obvious raise in the mean alveolar wall thickness when it was compared to control and NIC+AG groups. This was in harmony with the work done by Xu et al. [46]. El-Sokkary et al. [2] reported that the lung is the chief organ which is highly liable to free radical generation after cigarette smoke. Also, Trombino et al. [47] and Luqman and Rizvi [48] observed interstitial infiltration of inflammatory cells, degenerative changes of both and alveolar epithelium and interstitial cells in addition to interstitial infiltration of inflammatory. These changes could be explained by chronic inflammation caused by NIC administration [49]

Many researches proved that lung inflammation is linked with increased expression of pro-inflammatory cytokines that play a role in the intercellular signals that attract the cells and modulate its function [50]. It was reported that the airway epithelium is an abundant source of chemokines/ cytokines which attract both macrophages and neutrophils [51]. Activated neutrophils can result in wide spread inflammation of the lung tissue, destruction of basement membrane of alveolar capillary membrane and increase of its permeability. Moreover, neutrophils can discharge destructive mediators, as oxidants and cytokines which resulted in epithelial-vascular barrier injury [52,53].

Some studies proved that long-term exposure to NIC cause sodium channel receptors inactivation leading to thickening of the airway wall owing to an imbalance of apoptosis and cell proliferation. Additionally, the lining cells of bronchioles were shredded, had darkly stained nuclei and some mucous was detected inside their lumena. The raise in luminal mucus might be due to increased assembly of mucins by goblet cells, hyperplasia and/or metaplasia of goblet cell, accumulation of inflammatory cells and cell debris. Moreover, it was suggested that mucin production can be also enhanced by signaling initiated by TGF- $\beta 1$ [54]. Consequently, adhesion of the mucus to the cell surface results in reduction of mucociliary clearance and causes withholding of and pathogens and pollutants [55]. Moreover, fibroblast growth receptors and fibroblast growth factor were detected in the smooth muscle of airway, blood vessels and airway epithelial cells of smokers [56]

On the other hand, treatment with AG significantly decreased these histological changes. This was revealed by nearly normal appearance of bronchi, bronchioles and alveoli. Moreover, inter alveolar septae thickness, amount of collagen fibers and congestion of blood vessels was decreased. This improvement was obvious statistically by the significant increase in MLI and decrease in the mean alveolar thickness. These results were in conformity with Li et al. [57] who found that AG treatment reduced myeloperoxidase activity in the lung tissue and the levels of TNF- $\alpha$, IL- $1 \beta$, and also reduce IL- 6 in lung and bronchoalveolar lavage fluid which in turn result in improvement of histological pictures of lung tissue. Furthermore, AG blocked the activation of nuclear factor (NF) $-\kappa \mathrm{B}$ indicating its anti-inflammatory effects. The beneficial effect of AG can be also proved when it was administered with gentamicin, it was found to improved tissue morphology, reduced oxygen free radicals and lipid peroxidation associated renal injury, restored NO level and inhibited the inflammatory mediators [58]

In the current work, immune-histochemical staining of lung section from NIC group revealed an obvious elevation in the mean area\% of TGF $\beta 1$ immuno-expression and mean number of Bax immune positive cells. On the contrary, NIC+AG group showed a highly significant decrease of both parameters when compared to NIC group. The close interaction among inflammation, oxidative stress, and growth factors in the lung airways has been cleared. TGF-beta regulates extracellular matrix production and plays a vital function in the progression of organ fibrosis. TGF-beta 1 increases collagen, TIMP- 1 and MMP- 2 and decreases TIMP-2 and interstitial collagenases [17].

The association between TGF-beta and the inflammatory process is explained by its ability to increase vascular permeability during lung injury. It acts by decreasing the gap junctions between the epithelial cells therefore; it can be considered an essential mediator of lung inflammation [15]. Bonniaud et al. [59] narrated that over-expression of a lung-inducible TGF- $\beta 1$ trans-gene can result in progressive pulmonary fibrosis and elevated levels of matrix proteinases and extracellular matrix components.

The raise in the mean number of Bax immune-positive cells which were detected in NIC treated group in the present work can be proved by many studies. The increased expression of Bax was detected in COPD lungs [60] indicating that NIC can activate apoptosis. Also, Bax expression and the associated apoptosis was increased in polycyclic aromatic hydrocarbon exposed Lung [18]. Immuno-histochemical assessment of Bax in lung tissue relates well with apoptotic process and the expression of other apoptosis mediators [61]. Apoptotic cells might liberate oxidants, intracellular proteases and inflammatory mediators [62]. An early change and redistribution occurs in the intracellular localization of Bax in cells undergoing apoptosis and this appears to be important for Bax to induce cell death. Additionally, it was reported that Bax increases the opening of the mitochondrial voltage-dependent anion channel (VDAC) which can be also a mechanism for induction of cell apoptosis [19].

Notably, NIC+AG group displayed marked decline of mean area $\%$ of TGF $\beta 1$ immuno-expression and mean number of Bax immune positive cells when compared to NIC group.AG treatment markedly lessened iNOS expression and its activity in the lung tissue, and this phenomenon markedly hindered the inflammatory response [63]. Besides, AG was found to be protective against glutamate-induced 
Citation: Attia GM, Nader MA, Elmansy RA, Elsaed WM (2017) Agmatine Ameliorates Nicotine Induced Lung Injury in Rats through Decrease TGF-ß1 and Bax Immunoexpression and by Anti-oxidative Sress Pathway: Histological, Immunohistochemical and Biochemical Study. J Cytol Histol 8: 458. doi: 10.4172/2157-7099.1000458

Page 8 of 9

necrotic neuronal cell death and facilitates neurological functions recovery by reducing inflammation and apoptosis in acute spinal cord compression [64]. Furthermore, AG can protect against mitochondrial swelling probably by acting as a free radical scavenger preventing Ca2+-dependent induction of mitochondrial permeability transition (MPT) [65], these effects are concerned in apoptotic cell loss. Thus, mitochondrial protection can explain the general cyto-protective actions of AG in several body systems and prove its useful actions in a variety of illness models.

\section{Conclusion}

From the present work, it could be concluded that AG can ameliorate the biochemical and histopathological changes in the lung tissue induced by nicotine administration. Such ameliorating effect of AG was most probably exerted by decreasing lipid peroxidation and TGF $\beta 1$ immuno-expression in addition to its anti-apoptotic effect. Therefore, when intake of nicotine cannot be avoided, AG could be coadministered with it to minimize its hazardous effect on the lung. This work revealed that AG distinctly reversed all the alterations induced by nicotine administration for 9 weeks in rats.

\section{Clinical implication}

These findings may be helpful in future clinical studies.

\section{Limitation to the Study}

The results of this study are limited by the low number of animals used. The use of variable concentrations of NIC and AG in subsequent studies woud be valiabel.

\section{Conflict of Interest}

The authors announced conflict of interest linked to our protocol.

\section{References}

1. Shaw M, Mitchell R, Dorling D (2000) Time for a smoke? One cigarette reduces your life by 11 minutes. BMJ 320: 53.

2. El-Sokkary GH, Cuzzocrea S, Reiter RJ (2007) Effect of chronic nicotine administration on the rat lung and liver: beneficial role of melatonin. Toxicology 239: 60-67.

3. Carpagnano GE, Kharitonov SA, Resta O, Foschino-Barbaro MP, Gramiccioni $\mathrm{E}$, et al. (2003) 8-Isoprostane, a marker of oxidative stress, is increased in exhaled breath condensate of patients with obstructive sleep apnea after night and is reduced by continuous positive airway pressure therapy. Chest 124 : 1386-1392.

4. Hackett NR, Heguy A, Harvey BG, O'Connor TP, Luettich K, et al. (2003) Variability of antioxidant-related gene expression in the airway epithelium of cigarette smokers. Am J Respir Cell Mol Biol 29: 331-343.

5. Gvozdjakova A, Kucharska J, Gvozdjak J (1992) Effect of smoking on the oxidative processes of cardiomyocytes. Cardiology 8: 81-84.

6. Ateyya H, Nader MA, Attia GM, El-Sherbeeny NA (2017) Influence of alphalipoic acid on nicotine-induced lung and liver damage in experimental rats. Can J Physiol Pharmacol 95: 492-500.

7. Zhu MY, Iyo A, Piletz JE, Regunathan S (2004) Expression of human arginine decarboxylase, the biosynthetic enzyme for agmatine. Biochim Biophys Acta 1670: 156-164

8. Molderings GJ, Haenisch B (2012) Agmatine (decarboxylated L-arginine) physiological role and therapeutic potential. Pharmacol Ther 133: 351-365

9. Galea E, Regunathan S, Eliopoulos V, Feinstein DL, Reis DJ (1996) Inhibition of mammalian nitric oxide synthases by agmatine, an endogenous polyamine formed by decarboxylation of arginine. Biochem J 316: 247-249.

10. Hong S, Kim CY, Lee JE, Seong GJ (2009) Agmatine protects cultured retinal ganglion cells from tumor necrosis factor-alpha-induced apoptosis. Life Sci 84: 28-32.
11. Uzbay TI (2012) The pharmacological importance of agmatine in the brain. Neurosci Biobehav Rev 36: 502-519.

12. Su RB, Wei XL, Zheng JQ, Liu Y, Lu XQ, et al. (2004) Anticonvulsive effect of agmatine in mice. Pharmacol Biochem Behav 77: 345-349.

13. Ruiz-Durantez E, Llorente J, Ulibarri I, Pineda J, Ugedo L (2003) Agmatinemorphine interaction on nociception in mice. Ann N Y Acad Sci 1009: 133-136.

14. Zomkowski AD, Hammes L, Lin J, Calixto JB, Santos AR (2002) Agmatine produces antidepressant-like effects in two models of depression in mice. Neuroreport 13: 387-391.

15. Dhainaut JF, Charpentier J, Chiche JD (2003) Transforming growth factor-beta a mediator of cell regulation in acute respiratory distress syndrome. Crit Care Med 31: 258-S264.

16. Stevens T, Conwell DL, Zuccaro G (2004) Pathogenesis of chronic pancreatitis an evidence-based review of past theories and recent developments. Am J Gastroenterol 99: 2256-2270.

17. Mateescu G, Comanescu M, Mehedinti R, Niculescu Z, Bold A (2010) Immunohistochemical expression of growth factors in the exocrine pancreas of patients with chronic liver diseases. Rom J Morphol Embryol 51: 303-307.

18. Ghanem MM, Battelli LA, Mercer RR, Scabilloni JF, Kashon ML (2006) Apoptosis and Bax expression are increased by coal dust in the polycyclic aromatic hydrocarbon-exposed lung. Environ Health Perspect 114: 1367-1373.

19. Wolter KG, Hsu YT, Smith CL, Nechushtan A, Xi XG (1997) Movement of Bax from the cytosol to mitochondria during apoptosis. J Cell Biol 139: 1281-1292.

20. Li X, Liu Z, Jin H, Fan X, Yang X, et al. (2014) Agmatine protects against zymosan-induced acute lung injury in mice by inhibiting NF-kappaB-mediated inflammatory response. Biomed Res Int 14: 583-736.

21. Morley BJ, Garner LL (1990) Light-dark variation in response to chronic nicotine treatment and the density of hypothalamic alpha-bungarotoxin receptors. Pharmacol Biochem Behav 37: 239-245.

22. Bhutada P, Mundhada Y, Humane V, Rahigude A, Deshmukh P, et al. (2012) Agmatine, an endogenous ligand of imidazoline receptor protects against memory impairment and biochemical alterations in streptozotocin-induced diabetic rats. Prog Neuropsychopharmacol Biol Psychiatry 37: 96-105.

23. Stevens WC, Eger El, White A, Halsey MJ, Munger W, et al. (1975) Comparative toxicities of halothane, isoflurane, and diethyl ether at subanesthetic concentrations in laboratory animals. Anesthesiology 42: 408-419.

24. Friedewald WT, Levy RI, Fredrickson DS (1972) Estimation of the concentration of low-density lipoprotein cholesterol in plasma, without use of the preparative ultracentrifuge. Clin Chem 18: 499-502.

25. Bradford MM (1976) A rapid and sensitive method for the quantitation of microgram quantities of protein utilizing the principle of protein-dye binding. Anal Biochem 72: 248-254

26. Theory \& Practice of histological techniques (2008) (Edn 9) phladelphia Churchill Livingston.

27. Hsu SM, Raine L, Fanger H (1981) The use of antiavidin antibody and avidinbiotin-peroxidase complex in immunoperoxidase technics. Am J Clin Pathol 75: 816-821.

28. Knudsen L, Weibel ER, Gundersen HJ, Weinstein FV, Ochs M (2010) Assessment of air space size characteristics by intercept (chord) measurement: an accurate and efficient stereological approach. J Appl Physiol) 108: 412-421.

29. Nistor A, Simionescu M (1986) Uptake of low density lipoproteins by the hamster lung. Interactions with capillary endothelium. Am Rev Respir Dis 134 1266-1272.

30. Kolleck I, Schlame M, Fechner H, Looman AC, Wissel H, Rustow B (1999) $\mathrm{HDL}$ is the major source of vitamin $\mathrm{E}$ for type II pneumocytes. Free Radic Biol Med 27: 882-890.

31. Bjorkerud S, Bjorkerud B (1994) Lipoproteins are major and primary mitogens and growth promoters for human arterial smooth muscle cells and lung fibroblasts in vitro. Arterioscler Thromb 14: 288-298.

32. Vockeroth D, Gunasekara L, Amrein M, Possmayer F, Lewis JF (2010) Role of cholesterol in the biophysical dysfunction of surfactant in ventilator-induced lung injury. Am J Physiol Lung Cell Mol Physiol 298: 117-125.

33. McCrae KC, Weltman B, Alyward S, Shaw RA, Sowa MG (2008) The effect 
Citation: Attia GM, Nader MA, Elmansy RA, Elsaed WM (2017) Agmatine Ameliorates Nicotine Induced Lung Injury in Rats through Decrease TGF-ß1 and Bax Immunoexpression and by Anti-oxidative Sress Pathway: Histological, Immunohistochemical and Biochemical Study. J Cytol Histol 8: 458. doi: 10.4172/2157-7099.1000458

Page 9 of 9

of elevated dietary cholesterol on pulmonary surfactant function in adolescent mice. Pediatr Pulmonol 43: 426-434.

34. Gowdy KM, Fessler MB (2013) Emerging roles for cholesterol and lipoproteins in lung disease. Pulm Pharmacol Ther 26: 430-437.

35. Yeh YF, Huang SL (2004) Enhancing effect of dietary cholesterol and inhibitory effect of pravastatin on allergic pulmonary inflammation. J Biomed Sci 11: 599-606.

36. Lee JH, Lee DS, Kim EK, Choe KH, Oh YM, Shim TS (2005) Simvastatin inhibits cigarette smoking-induced emphysema and pulmonary hypertension in rat lungs. Am J Respir Crit Care Med 172: 987-993.

37. Nader MA, Gamiel NM, El-Kashef H, Zaghloul MS (2016) Effect of agmatine on experimental vascular endothelial dysfunction. Hum Exp Toxicol 35: 573-582.

38. Sudheer AR, Muthukumaran S, Devipriya N, Devaraj H, Menon VP (2008) Influence of ferulic acid on nicotine-induced lipid peroxidation, DNA damage and inflammation in experimental rats as compared to $\mathrm{N}$-acetylcysteine. Toxicology 243: 317-329.

39. Yamazaki H, Inoue K, Hashimoto M, Shimada T (1999) Roles of CYP2A6 and CYP2B6 in nicotine C-oxidation by human liver microsomes. Arch Toxicol 73 $65-70$.

40. Lee GT, Ha H, Lee HC, Cho YD (2003) Agmatine reduces hydrogen peroxide in mesangial cells under high glucose conditions. J Biochem Mol Biol 36: 251-257.

41. lizuka Y, Hong S, Kim CY, Yang WI, Lee JE, Seong GJ (2010) Protective mechanism of agmatine pretreatment on RGC-5 cells injured by oxidative stress. Braz J Med Biol Res 43: 356-358.

42. Church DF, Pryor WA (1985) Free-radical chemistry of cigarette smoke and its toxicological implications. Environ Health Perspect 64: 111-126.

43. Guo Y, Mishra A, Howland E, Zhao C, Shukla D, et al. (2015) Plateletderived Wnt antagonist Dickkopf-1 is implicated in ICAM-1/VCAM-1-mediated neutrophilic acute lung inflammation. Blood 126: 2220-2229.

44. Rodella LF, Filippini F, Bonomini F, Bresciani R, Reiter RJ, et al. (2010) Beneficial effects of melatonin on nicotine-induced vasculopathy. J Pineal Res 48: 126-132.

45. Raasch W, Schafer U, Chun J, Dominiak P (2001) Biological significance of agmatine, an endogenous ligand at imidazoline binding sites. Br J Pharmacol 133: $755-780$.

46. Xu GH, Shen J, Sun P, Yang ML, Zhao PW (2015) Anti-inflammatory effects of potato extract on a rat model of cigarette smoke-induced chronic obstructive pulmonary disease. Food Nutr Res 59: 28879

47. Trombino S, Cesario A, Margaritora S, Granone P, Motta G (2004) Alpha7nicotinic acetylcholine receptors affect growth regulation of human mesothelioma cells: role of mitogen-activated protein kinase pathway. Cancer Res 64: 135-145.

48. Luqman S, Rizvi SI (2006) Protection of lipid peroxidation and carbony formation in proteins by capsaicin in human erythrocytes subjected to oxidative stress. Phytother Res 20: 303-306.

49. Piipari R, Savela K, Nurminen T, Hukkanen J, Raunio H et. al. (2000) Expression of CYP1A1, CYP1B1 and CYP3A, and polycyclic aromatic hydrocarbon-DNA adduct formation in bronchoalveolar macrophages of smokers and nonsmokers. Int J Cancer 86: 610-616.

50. Babu BI, Malleo G, Genovese T, Mazzon E, Di PR (2009) Green tea polyphenols ameliorate pancreatic injury in cerulein-induced murine acute pancreatitis. Pancreas 38: 954-967.

51. Papi A, Luppi F, Franco F, Fabbri LM (2006) Pathophysiology of exacerbations of chronic obstructive pulmonary disease. Proc Am Thorac Soc 3: 24255-251.

52. Huang X, Zhao YY (2012) Transgenic expression of FoxM1 promotes endothelial repair following lung injury induced by polymicrobial sepsis in mice. PLoS One 7: e50094.
53. Hoth JJ, Wells JD, Hiltbold EM, McCall CE, Yoza BK (2011) Mechanism of neutrophil recruitment to the lung after pulmonary contusion. Shock 35: 604-609.

54. Yoshida T, Tuder RM (2007) Pathobiology of cigarette smoke-induced chronic obstructive pulmonary disease. Physiol Rev 87: 1047-1082.

55. Boucher RC (2004) Relationship of airway epithelial ion transport to chronic bronchitis. Proc Am Thorac Soc 1: 66-70.

56. Kranenburg AR, de Boer WI, Van Krieken JH, Mooi WJ, Walters JE (2002) Enhanced expression of fibroblast growth factors and receptor FGFR-1 during vascular remodeling in chronic obstructive pulmonary disease. Am J Respir Cell Mol Biol 27: 517-525.

57. Li X, Liu Z, Jin H, Fan X, Yang $X$ et. al. (2014) Agmatine protects agains zymosan-induced acute lung injury in mice by inhibiting NF-kappaB-mediated inflammatory response. Biomed Res Int 2014: 583736

58. El-Kashef DH, El-Kenawi AE, Abdel RM, Suddek GM, Salem HA (2016) Agmatine improves renal function in gentamicin-induced nephrotoxicity in rats. Can J Physiol Pharmacol 94: 278-286.

59. Bonniaud P, Kolb M, Galt T, Robertson J, Robbins C, et al. (2004) Smad3 nul mice develop airspace enlargement and are resistant to TGF-beta-mediated pulmonary fibrosis. J Immunol 173: 2099-2108.

60. Imai K, Mercer BA, Schulman LL, Sonett JR, D'Armiento JM (2005) Correlation of lung surface area to apoptosis and proliferation in human emphysema. Eur Respir J 25: 250-258.

61. Plataki M, Koutsopoulos AV, Darivianaki K, Delides G, Siafakas NM, et al. (2005) Expression of apoptotic and antiapoptotic markers in epithelial cells in idiopathic pulmonary fibrosis. Chest 127: $266-274$.

62. Vandivier RW, Henson PM, Douglas IS (2006) Burying the dead: the impact of failed apoptotic cell removal (efferocytosis) on chronic inflammatory lung disease. Chest 129: 1673-1682.

63. Olmos G, DeGregorio-Rocasolano N, Paz RM, Gasull T, Assumpcio BM (1999) Protection by imidazol (ine) drugs and agmatine of glutamate-induced neurotoxicity in cultured cerebellar granule cells through blockade of NMDA receptor. Br J Pharmacol 127: 1317-1326.

64. Condello S, Curro M, Ferlazzo N, Caccamo D, Satriano J, et al. (2011) Agmatine effects on mitochondrial membrane potential and NF-kappaB activation protec against rotenone-induced cell damage in human neuronal-like SH-SY5Y cells. J Neurochem 116: 67-75

65. Battaglia V, Grancara S, Satriano J, Saccoccio S, Agostinelli E, et al. (2010) Agmatine prevents the $\mathrm{Ca}(2+)$-dependent induction of permeability transition in rat brain mitochondria. Amino Acids 38: 431-437. 